\title{
Title: The Usability of Unmanned Aerial Vehicles (UAVs) for Pedestrian Observation
}

\author{
Authors \\ Keunhyun Park, Department of Landscape Architecture and Environmental Planning, Utah State \\ University, Logan, UT, USA \\ Reid Ewing, Department of City \& Metropolitan Planning, University of Utah, Salt Lake City, \\ UT, USA
}

Corresponding Author:

Keunhyun Park, 4005 Old Main Hill, Logan, UT, USA 84322-4005, keunhyun.park@usu.edu

Bios

Keunhyun Park (keunhyun.park@usu.edu) is an assistant professor in Department of Landscape Architecture and Environmental Planning at Utah State University. His research interests include technology-driven behavioral research in public space and behavioral outcomes of smart growth.

Reid Ewing (ewing@arch.utah.edu) is a distinguished professor and distinguished chair for Resilient Places at the University of Utah and a columnist for Planning magazine. He is a coauthor of Measuring Urban Design: Metrics for Livable Places.

This is a pre-print version. To access the final version, go to:

http://journals.sagepub.com/doi/full/10.1177/0739456X18805154 or send me a message at https://www.researchgate.net/profile/Keunhyun Park 


\begin{abstract}
The monitoring of pedestrian activity is challenging, primarily because its traffic levels are typically lower and more variable than those of motorized vehicles. Compared with other on-theground observation tools, unmanned aerial vehicles (UAVs) could be suitable for counting and mapping pedestrians in a reliable and efficient way. Thus, this study establishes and tests a new method of pedestrian observation using UAVs. The results show that UAV observations demonstrate high levels of inter-rater reliability $(\mathrm{ICC}=0.99)$ and equivalence reliability (Cronbach's a $=0.97$ (with on-the-ground counts); 0.73 (with Google Street View)). Practical implications of the new tool are discussed.
\end{abstract}

\title{
Keywords
}

Direct observation, Pedestrian counting, Pedestrian monitoring, Unmanned aircraft systems, UAS

\section{Introduction}

In the fields of urban planning and design, observation is one of the classic, essential methods of studying the interaction between people and places. Jane Jacobs (1961, xiii) urges urban researchers to "look closely at real cities ... and think about what we see." From observing urban residents and their interactions on sidewalks, she found the critical conditions of built environments for a vital urban life (Jacobs 1961), which are still considered valid in 21st-century cities (Sung, Lee, \& Cheon 2015). As with William H. Whyte's (1980) case, systematic direct observation fosters researchers' understanding of the substance of urban public life in an objective and measurable way. In direct observation, a researcher observes the activities of humans rather than intervening in their behavior, and then documents, analyzes, and interprets 
user behaviors to determine how they use space (Gehl \& Svarre 2013). This translates directly into measures of livability, physical activity, and vehicle trip reduction in cities (Ewing and Clemente 2013; Mehta 2013).

As a method to assess physical activity and its contexts, systematic observation is advantageous in that it is an objective method and allows for the simultaneous data collection of both behavioral and environmental information (McKenzie and van der Mars 2015). This is important because physical activity is "place-dependent" occurring in specific locations (Sallis 2009). Thus, several systematic observation tools for assessing physical activity have been developed in various contexts such as parks (McKenzie et al. 2006), schools (McKenzie et al. 2000), playgrounds (Ridgers et al. 2010), and natural areas (Sasidharan and McKenzie 2014). The observation data then contributes to the better understanding of how environmental interventions impact physical activity (for review papers of this subject, see Davison and Lawson 2006; Evenson et al. 2016; Ferreira et al. 2007).

Monitoring pedestrian volume and activities is an essential task in transportation planning and design. Pedestrian traffic data can be applied to assess the safety and the capacity of existing streets, provide input to traffic forecast models, measure the impact of changes before and after a street design intervention, and ultimately determine the efficient allocation of resources (Diogenes et al. 2007).

Two main approaches of direct observation in streets are manual observation and automatic counts, both of which have pros and cons. Although manual counts are labor-intensive and errorprone, which results from subjective observations by individuals collecting the data, manual observation captures not just the number of people but also their behaviors or attributes (Diogenes et al. 2007; US FHWA 2013). The other approach, automatic count technologies, 
make use of devices installed in set locations, so automatic observation is a practical and less costly method of collecting ongoing and consistent data (SCAG 2013; US FHWA 2013). However, it often results in the collection of inaccurate, limited information (e.g., counts, not activities) (Greene-Roesel et al. 2008; Schneider et al. 2009). A more accurate and thorough observation method is the use of video cameras, which allow subsequent verification (Diogenes et al. 2007; Figliozzi et al. 2014; Greene-Roesel et al. 2008). However, cameras are costly and subject to theft, vandalism, and occasional malfunctions (US FHWA 2013; Ryus et al. 2014; SCAG 2013). Another challenge is that the above-mentioned methods take place within a limited number of locations which may not represent the entire area of interest.

To fill in the gap of existing tools, this study tests a new method of pedestrian observation: the use of unmanned aerial vehicles (UAVs), also known as drones. UAVs carrying a video camera combine the advantages of human observation and video recording (Park \& Ewing 2017). As UAVs cover a greater area in a shorter amount of time than other methods, they are expected to save time and money required for data collection. UAV-recorded video files allow for postobservation data processing and validation (Lenhart et al. 2008). In addition, as they capture not only the number of pedestrians but also their activities, attributes, and spatial patterns in a more accurate way, they are also more informational.

This study tests the reliability of UAV observation on pedestrian counts and explores practical implications of the new tool in pedestrian studies. The use of UAVs has become popular in environmental studies such as geology (Vasuki et al. 2014), forestry (Getzin et al. 2012; Lin et al. 2015), agriculture (Torres-Sanchez et al. 2014), and construction engineering (Siebert \& Teizer 2014), but to date, only a few studies have tested UAVs in pedestrian observation. A more 
efficient and reliable observation tool could lead to savings in both time and money for urban planners and designers.

\section{Literature review}

Over the years, methods of collecting useful traffic data have evolved with advancements in technology, including induction loops, overhead radar sensors, and fixed video camera systems (Coifman et al. 2006; Papageorgiou et al. 2003; Ryus et al. 2014). Use of these traditional devices for traffic surveillance and monitoring, however, have raised concerns about their limited extent of coverage, the high cost of installation and maintenance, inflexibility of response to unexpected events, and other issues (Coifman et al. 2006; Barmpounakis et al. 2017). Recently, researchers have examined the applicability of UAVs to traffic and roadway incident monitoring because of their low cost, easy deployment, high mobility, and large view scope (Lee et al. 2015; Kanistras et al. 2014). Although UAVs were first introduced for military missions, their use has been recently expanded to civil applications, supported by the UAV industry, which has steadily produced smaller and lower-cost aircraft (Mahadevan 2010). Civil applications have primarily involved the use of UAVs in aerial photography, especially with the latest advances in sensor technologies (Budiyono 2008; Cheng 2015), and the transportation engineering field has applied UAVs as a novel and cost-effective method of collecting massive trajectory data from road arterials and replacing old approaches on fixed spots (e.g., stationary cameras; Barmpounakis et al. 2017).

Earlier UAV research aimed at identifying their potential for monitoring vehicle traffic (Moranduzzo \& Melgani 2014; Wang, Chen, \& Yin 2016). Ro et al. (2007) tested the applicability of UAVs to highway traffic monitoring and concluded that UAVs could play a 
significant role in the ITS (Intelligent Transportation Systems) infrastructure. Coifman et al. (2006) used a UAV to conduct several empirical tasks in urban streets such as determining the level of service (LOS), estimating average annual daily travel (AADT), measuring intersection operating conditions, and creating origin-destination flows. Recent studies have focused on the post-processing of aerial videos using advanced modeling and machine learning for extracting traffic information (Li 2008; Lenhart et al. 2008). Although detecting and tracking vehicles by UAV videos have been the focus of increasing investigation by transportation scholars, the detection accuracy of existing technology usually is lower than $90 \%$, so obtaining more comprehensive information, such as detailed trajectory data on drivers, is virtually impossible (Wang et al. 2016).

Recently, several researchers have explored the potential of using UAVs for pedestrian detection and tracking (Gaszczak et al. 2011; Ma et al. 2016; Portmann et al. 2014). However, pedestrian detection from images obtained from UAVs poses some challenges resulting from the small size of objects, the motion of the UAV, and the low quality of images (Ma et al. 2016). As a result, automatic object detection has become a challenging task. As an alternative, several researchers employed thermal imagery (Gaszczak et al. 2011), but it was still problematic because of the variability of human thermal signatures (Ma et al. 2016). Thus, as the current technology of automatic pedestrian detection and tracking remains too limited to be applied in common practice (US FHWA 2013), this study relies on the manual observation of UAV-recorded video files of pedestrian movements while reaping the benefits of high-altitude, high-quality video observation.

Pedestrian volume has been mainly measured through direct observation and related to the characteristics of nearby built environments. As pointed out by the FHWA (2013), the methods 
of pedestrian counting have been inconsistent in applications. In the urban design field, the authors of several studies counted pedestrians passing a specific point or a line where someone was observing (Ameli et al. 2015; Hajrasouliha and Yin 2015; Rodríguez et al. 2009), while other studies recorded pedestrians that passed the observer from the following direction, as the observer walked down a sidewalk (Alasadi 2016; Ernawati et al. 2016; Ewing et al. 2016; Maxwell 2016; Ozbil et al. 2011; Yin 2017).

To identify urban design measures and streetscape variables that explain pedestrian traffic volumes, Reid Ewing and his colleagues (Ewing and Clemente 2013; Ewing et al. 2016) measured pedestrian volume as the average number of people encountered on four passes up and down a given block face. An observer walked the length of the segment one time for each count and included every pedestrian he or she encountered during that exercise. Then they established the reliability of manual counts against web-based street images. This study utilizes their methodology of pedestrian counting. Their protocol has been applied in subsequent studies throughout the world (Alasad, 2016; Ernawati et al, 2016; Ewing et al.,2016; Hamidi and Moazzeni, 2018; Maxwell 2016; Yin 2017).

\section{Methods}

\section{Study sites}

The study sites include 26 block faces in Salt Lake City, Utah. The study area consists of typical car-oriented streets in the western United States, which is generalizable to average places such as medium-sized cities of average density (Figure 1). The specific addresses are State Street from $400 \mathrm{~S}$ to Williams Avenue and Main Street from $400 \mathrm{~S}$ to Fremont Avenue in Salt Lake City, Utah. This section is a part of the "Life on State" project, a collaborative corridor improvement 
project among regional partners, including Salt Lake City, Utah Department of Transportation (UDOT), Utah Transit Authority (UTA), Wasatch Front Regional Council (WFRC), and Salt Lake County.

A block face, the frontage on one side of a block, is the unit of observation. If a block is too long, it is divided into about 700-foot subsections, so that an observer can conduct an on-the-ground observation concurrently with the UAV flight.

"Figure 1 here"

\section{Observation process}

The observations entail the use of a UAV, DJI Phantom 4 Professional, which carries a fully stabilized 4K video camera. Each observation of a street segment involved three steps (Figure 2): 1) An operator planned a flight path on the centerline of a roadway that accounts for boundaries and obstacles (e.g., powerlines) and collected contextual information such as weather (e.g., temperature) and specific events (e.g., a car accident, construction work); 2) after flying the UAV up to an appropriate height (50-70 feet), the operator set flight waypoints - usually a start and an end point —on the pre-planned path; and 3) the UAV automatically flew through the waypoints twice (i.e., two passes up and down a given block face) and recorded the area at a flight speed of about $4 \mathrm{mph}(1.8 \mathrm{~m} / \mathrm{s})$, similar to walking speed. The flight height, $50-70$ feet, was chosen to allow identification of the gender, age group, and travel mode of pedestrians, making a tradeoff between data accuracy and flight safety.

After the on-site flights, an observer collected pedestrian information and street facilities by watching the recorded videos. Each pedestrian is coded with estimated information regarding gender (male or female), age group (senior, adult, or child), and mode of transportation 
(unassisted pedestrian, assisted pedestrian, or bicyclists). Then, the information was aggregated by block face to provide summary counts. Street facilities include bus stops, food vendors, bike racks, trash cans, benches, planters, etc. To test inter-rater reliability of pedestrian counts from UAV observation, an additional observer watched the same video and collected pedestrian data.

"Figure 2 here"

Each UAV operation followed safety regulations established by the U.S. Federal Aviation Administration (2016). The researchers obtained approval from the Institutional Review Board at the the University of Utah (approved March 14, 2017). Also, the Utah Department of Transportation (UDOT) approved this study using drones in its right of way. In addition, upon a request by the UDOT, the author obtained an encroachment permit. Similar to previous pedestrian observation studies (Ewing \& Clemente 2013; Ewing et al. 2016), this study conducted all field observations between 10 AM and 4 PM on weekdays in April 2017. The field work took place only on days in which no rain or strong winds occurred.

To test the appropriateness and effectiveness of UAV as a tool for collecting pedestrian volume data, this study compares results of the UAV data collection approach with those of on-theground observations, the present gold standard for this kind of research (Figure 3). On-theground observations were conducted concurrently with the UAV flights, meaning that a human observer walked the length of the block face twice at the same speed as the UAV and counted every pedestrian she encounted during that exercise. The resulting data was the average pedestrian counts of four passes, i.e., total counts divided by four. Both observations collected the same set of data: pedestrian counts by gender, age group, and mode of transportation.

"Figure 3 here" 


\section{Analyses}

This study uses two tests of reliability of pedestrian counts to determine the reliability of the UAV measures. Both the UAV and on-the-ground counts are the average of the two passes up and down a block face.

The first test of reliability determines equivalence, the extent to which variables measure the same underlying construct, which, in this case, is pedestrian activity. Equivalence reliability is determined by relating the values of the variables to highlight the degree of their relationship or association (Ewing \& Clemente 2013). This study compares pedestrian counts by the UAV to on-the-ground observation and counts on two street-view websites: Google Street View (mostly photographed in May 2016) and Bing StreetSide (mostly shot in August 2014), both of which offer a reliable alternative to pedestrian counts (Campanella 2017; Ewing and Clemente 2013; Yin et al. 2015).

Equivalence reliability is judged with Cronbach's alpha, widely used in social science to determine if items measure the same thing consistently. If independent counts - one based on UAV observation, one on on-the-ground observation, and two on street imagery - agree, one can assume that the UAV counts are reliable measures of pedestrian activity. Some professionals require reliability of 0.70 or higher before they will use an instrument (Ewing \& Clemente, 2013).

The other test is a test of inter-rater reliability for the counts from two observers watching the same UAV-recorded video files. To check for the inter-rater reliability, this study uses intraclass correlation coefficients (ICCs) as a measure of agreement. Using ICCs, researchers analyze the consistency, or conformity, of measurements taken by multiple observers measuring the same 
quantity (Gwet 2014; Shrout and Fleiss 1979). In particular, this study used the one-way Analysis of Variance (ANOVA) as a form of the ICC, representing the ratio of between-group variance to total variance of counts (Shrout \& Fleiss 1979). The ICC was computed not only for the total number of pedestrians but for the numbers by gender, age group (senior, adult, child), and mode of transportation (unassisted pedestrian, assisted pedestrian, and bicyclists).

\section{Results}

\section{Summary of UAV observations}

For the 26 block faces, 90 pedestrians (average 3.5 per block face) were counted from the UAV observations (Figure 4). The number of users per block ranged from 0 to 13 with a standard deviation of 3.1. The UAV observations recorded more males ( 2.6 on average) than females (0.9). The primary age group was adults (2.8 persons), followed by seniors $(0.4)$ and children (0.1). The most common mode of transportation was unassisted walking (3.2 persons), followed by bike (0.2). There were almost no assisted pedestrians (e.g., skaters, wheelchairs, or strollers) (0.02 on average).

"Figure 4 here"

Next, the time needed for two observation methods are compared in Table 1. On-the-ground observations required 194 minutes in total for 26 block faces. This includes an average of two minutes of pre- and post-setting time. On the average block face with a length of 820 feet (250 meters), on-the-ground observation took 7.46 minutes. On the other hand, the UAV observations required 26 minutes for pre/post-flight setting such as setting waypoints, taking off, and landing, 71 minutes for actual flights, and 142 minutes for video counts by an observer, meaning 239 
minutes in total for 13 street segments, or 26 block faces because a single flight could observe both sides of street. Video counts took approximately twice of the flight time because the observer had to observe both sides and occasionally pause and rewind the video. This equals to 9.19 minutes per block face. This result shows that a UAV observation needs an additional 1.73 minutes, or extra $23 \%$ of the time, per block face area under the current research protocol.

"Table 1 here"

However, as explored in the introduction and discussion sections, a UAV can cover larger areas in one observation than a human observer. If a flight area and speed are doubled (1,500 feet and $8 \mathrm{mph}$ ), both of which are realistic assumptions, the required time will become half -4.6 minutes per block face, meaning 2.9 minutes (or 38\%) of time saved compared to on-the-ground observations. In terms of money spent on both methods, apart from the labor costs (which are basically proportional to the time spent), the UAV observation required the purchase of a UAV and necessary accessories (approximately $\$ 2,000$ ) and a test fee for a remote pilot certificate $(\$ 150)$.

\section{Reliability of the UAV observations}

To check the equivalence reliability of the UAV observation method, this study calculated the Cronbach's alpha of the results for the UAV compared to those of three other observation methods - on-the-ground observation and two street-view websites. Table 2 shows that the alpha values are high for UAV vs. on-the-ground counts comparison (0.97) and UAV vs. Google counts comparison (0.73). The lower level of reliability with Bing counts (0.46) was similarly reported in a previous study (Ewing \& Clemente 2013) and might be attributed to the time and seasonal difference - April 2017 (UAV observation) vs. August 2014 (Bing StreetSide). 
"Table 2 here"

To check the inter-rater reliability of the UAV observation method, this study calculated the ICCs between data from a primary observer and an additional observer watching the same video files taken by the UAV. Table 3 shows that the two observers saw a similar average number of pedestrians per target area (3.46 persons and 3.56 persons). The UAV counts between two observers demonstrate a high level of inter-rater reliability (ICC $>0.8)$ for all categories except the child group. Reliability measures for assisted pedestrians and bicycle riders were not calculated due to too small counts.

"Table 3 here"

\section{Discussion}

\section{Comparison of different pedestrian observation methods}

In this study, observations by the UAV yielded reliable results. From the results of the analysis, field notes, and the literature, we compared and discussed four main tools of pedestrian observation - human eyes, video camera, automatic counter, and UAV (Table 4).

"Table 4 here"

A manual observation by human eyes has been a traditional and easy-to-implement approach in counting pedestrians and studying their activities. Jan Gehl and his team counted and mapped pedestrian activities in an intersection and found that many pedestrians occupied places not designed for them (Transport for London \& the Central London Partnership 2004), which later became a key motivation to redesign the Oxford Circus in London. Manual counting is not only 
portable but also capable of gathering detailed information about pedestrians (e.g., gender, age group, race/ethnicity, activity type). On the other hand, it is labor-intensive and prone to subjective data collection (Diogenes et al. 2007).

A more accurate and thorough way of counting manually is by using video cameras or time-lapse photography, for they allow subsequent verification. Since Whyte (1980) observed people in public plazas and streets in New York City and ascertained why some places were successful while others were not, video observation has been used in many pedestrian studies (Diogenes, et al. 2007; Figliozzi et al. 2014; Greene-Roesel et al. 2008). Unfortunately, video cameras are not only costly but also subject to theft, vandalism, and occasional malfunctions. Instead of installing expensive fixed cameras, a dashboard camera or online street images (e.g., Google Street View) can be affordable tools and provide reliable data (Campanella 2017; Ewing and Clemente 2013; Ewing et al. 2016). However, such methods have a limited view and are easily blocked by cars parked on the street or street furniture.

It is important to note significant work on automated pedestrian detection and behavior analysis using stationary cameras (Ge et al. 2012; Kilambi et al. 2008; Yan and Forsyth 2005; Xia et al. 2015). Using computerized algorithms, researchers have figured out ways to detect a frame-byframe change in pixels in a video image to tell whether or not objects in the image are pedestrians. Yin et al. (2015) used Google Street View for automatic pedestrian detection and tested its reliability. FHWA (2013) points out that advanced video image processing algorithms have not been incorporated into most commercial products yet, and thus, this method has the highest equipment costs.

The other approach, automatic count technologies, make use of devices installed in a set location, so the automatic observation is a practical and less costly method of collecting ongoing 
and consistent data (SCAG 2013; US FHWA 2013). However, it often results in the collection of inaccurate, limited information (Greene-Roesel et al. 2008; Schneider et al. 2009). A common source of inaccuracy in automatic counters is occlusion, or undercounting (i.e., only counting one person when multiple users are walking next to each other; Ryus et al. 2014). This effect was observed for various automatic counting tools including passive infrared, active infrared, and radio beam sensors, especially with higher pedestrian volumes (Arnberger et al. 2005; Ozbay et al. 2010, Ryus et al. 2014; Schneider et al. 2012). Also, pedestrians are less confined to fixed paths of travel (e.g., taking shortcuts off the sidewalk or crossing streets at unmarked crossing locations), which decrease the accuracy of sensor equipment counts.

As shown in this study, UAV-based pedestrian observation can be efficient, accurate, and informative. For one, a UAV can cover a larger area during each observation period than a human observer. We found that a UAV could fly as far as a remote pilot can see the aircraft about 1,500 - 2,000 feet. In addition, even in ten-lane streets, a camera on a UAV can capture both sides of the street, which reduces the observation time by half. These advantages would make the UAV useful for car-oriented and sprawling areas with wide roads and large blocks. After considering the additional time for video watching, this study found that UAV observation could save about 40 percent of the person-hours with an assumption that the observation area and speed could be twice $(1,500$ feet and $8 \mathrm{mph})$ that of manual observation.

Second, in UAV observation, a researcher can collect more accurate user data with the support of recorded video. Post-data collection analysis has the potential to estimate attributes of pedestrians (e.g., age, gender, travel mode), while that is a limitation of automated counters. Compared with a walking observer or a moving camera installed in a car (e.g., Google Street View), a UAV can move at a constant speed without any interrupting traffic, which provides 
more consistent data. While automatic pedestrian detection has seldom been used in UAV setting yet, future advancement in image processing technology would realize a more efficient pedestrian observation from UAV-recorded video data.

On the other hand, the utilization of UAVs has some limitations. UAV observation is more subject to survey area conditions such as weather, time, topography, or surrounding buildings. On a rainy or windy day, flying a UAV is not recommended for safety reasons. Even manual counts are typically done under good weather conditions, so this is not a major limitation. While a UAV can be equipped with a thermal camera to capture nighttime activities (Gaszczak et al. 2011; Ma et al. 2016), nighttime operation requires an operational waiver from most current UAV regulations including US FAA Part 107. The flight time of maximum 30 minutes is another limitation, which makes the method only suitable for momentary observation. Lastly, bird's-eyelevel observation complicates the identification of people behind obstacles (e.g., street trees or big trucks). In this case, the UAV might fly over the sidewalk, which requires greater care and may require property owner permission.

\section{Practical and social implications of the UAV observation}

When using a UAV to investigate pedestrian activities, researchers must consider practical implications and social complications of their method. For one, they must ensure that the remote pilot follows UAV operational rules governed by an aviation administration. For example, on June 21, 2016, the U.S. Federal Aviation Administration (U.S. FAA 2016) announced a rule called "Operation and Certification of Small Unmanned Aircraft Systems (Part 107)" for small UAVs of less than $55 \mathrm{lbs}(25 \mathrm{~kg})$. Part 107 requires that UAVs be registered, remain within the visual line-of-sight of the remote pilot, and not fly at night or above 400 feet (122 meters) above ground level. Also, a person operating a small UAV must hold (or be under the direct 
supervision of a person holding) a remote pilot certificate. One important rule of Part 107 regarding pedestrian observation is that a UAV must not fly directly above people. While an operator might be able to request a waiver from FAA, it is easier and safer to fly a UAV over the centerline of the road, as was done in this study, instead of the sidewalk.

Researchers must bear in mind that the deployment of UAVs in civil applications raises safety, ethical, and privacy issues (Finn and Wright 2012; Rapp 2009). When a UAV crashes on the street, it could seriously injure people or damage cars, facilities, and/or the ground. One legal review (Finn and Wright 2012) found that a UAV flight within or too close to a private property might lead to trespass or nuisance claims by homeowners. At the same time, however, they also found that privacy claims are limited to wherever "a UAV captures images that could have been obtained from civilian aircraft traveling in a legally authorized manner," that is, data already available to the public (Finn and Wright 2012, 642). As the use of UAVs becomes more popular with the public, a survey using a UAV on a public street may raise fewer concerns.

For both safety and reliability, researchers must ensure the provision of sufficient training to UAV pilots in advance and conduct a preliminary survey of study sites. If the observation process involves too much variation in data among different observers, observation data will not be reliable. Thus, researchers need to prepare an observation protocol, including the observation process, flight waypoints, speed, height, and camera shooting method. They could also set the flight height according to a survey purpose. For an accurate count of the number of users, a UAV could fly high (e.g., 100 feet) with minimum movement. On the other hand, to collect detailed user information, it must fly lower and more slowly (e.g., 30 60 feet) and observe pedestrians more carefully. 
While the results of this study show that the UAV method is reliable in counting the number of users by gender, age group, and mode, the less reliable category - child group - might be attributed to a teenager looking like an adult when there is a great distance between a person and a UAV. Thus, greater inter-rater reliability requires a more accurate survey protocol, sufficient observer training, and validation studies.

As one of its future applications, we found that the UAV-recorded video enables the researcher to survey spatial patterns of pedestrians in street environments. Figure 5 shows two mapping examples from the UAV observation. Pedestrians with their attributes (gender and age group) are mapped on the left map and the right map has the exact location of street furniture including bus stops, food vendors, bike racks, trash cans, benches, etc. Using those maps, an urban designer could conduct an exploratory analysis of street life and vitality (e.g., where senior people walk, women are populated, or the relationship between the presence of specific street furniture and pedestrian volume). For example, in Figure 5, a reader can see that senior people are hardly found in these streets and pedestrians are populated near bus stops or food vendors. The behavioral map could be drawn multiple times throughout the day or year, for an analysis of changes on pedestrian activity patterns.

"Figure 5 here"

\section{Limitations}

As a study examining the usability of a new observational method, this research involves several limitations. One is the limited size of the observation area, which allowed for a direct comparison to the on-the-ground observation. However, as this study has found that a UAV could cover a larger area, a subsequent study could determine the practical use of UAVs in 
streets by examining larger observation areas (e.g., 1,500 to 2,000 feet). In addition, the streets in this study might not have been a representative sample of the U.S. The average number of pedestrian per block face was only 3.6, which is relatively low. To ensure better generalizability, further research could include diverse samples such as downtown areas in a large city.

\section{Conclusions}

While some instruments for monitoring non-motorized traffic have been developed, no tool that ideally fits all situations is currently available. Compared to on-the-ground counting and online street imagery counting, this study demonstrates that UAV-based pedestrian counting is reliable, as previously verified in a setting of urban parks (Park \& Ewing 2017). Also, the inter-rater reliability between two observers watching the same UAV-video files is high. A UAV is capable of collecting more information via recorded video files that capture various characteristics of non-motorized traffic (e.g., attributes, behaviors, spatial patterns), and after it collects data, a technician can assess them. Given enough video data, computer vision and machine learning techniques could achieve an accurate autonomous analysis of pedestrian activities in the future. In addition, as the UAV can cover larger areas in a shorter time period, it is also more efficient. On the other hand, it may not be suitable for long-term monitoring or survey on under poor conditions (e.g., narrow streets, poor weather). Thus, depending on their purpose and context, planners and transportation engineers can select an appropriate counting method and use the acquired data to not only inform an analysis of existing street capacity and safety but also provide ideas for proper interventions on existing streets.

\section{Acknowledgement}

This research was supported by the Utah Agricultural Experiment Station, Utah State University, and approved as journal paper number 9132. The authors appreciate Utah Department of 
Transportation for approving the UAV flights in its right of way and issuing an encroachment permit.

\section{References}

Alasadi, R. (2016). Investigating spatial quality in urban settings: The assessment of walkability in the streets of Doha, Qatar (Doctoral dissertation, Qatar University (Qatar)).

Ameli, S. H., Hamidi, S., Garfinkel-Castro, A., \& Ewing, R. (2015). Do better urban design qualities lead to more walking in Salt Lake City, Utah?. Journal of Urban Design, 20(3), 393-410.

Arnberger, A., Haider, W., \& Brandenburg, C. (2005). Evaluating visitor-monitoring techniques: A comparison of counting and video observation data. Environmental Management, 36(2), 317-327. DOI: $10.1007 / \mathrm{s} 00267-004-8201-6$.

Barmpounakis, E. N., Vlahogianni, E. I., \& Golias, J. C. (2017). Unmanned Aerial Systems for Transportation Engineering: Current practice and future challenges. International Journal of Transportation Science and Technology. http://dx.doi.org/10.1016/j.ijtst.2017.02.001

Budiyono, A. (2008). Advances in unmanned aerial vehicles technologies. In International Symposium on Intelligent Unmanned System (pp. 1-13).

Campanella, R. (2017). People-Mapping Through Google Street View. Places Journal. https://placesjournal.org/article/people-mapping-through-google-street-view/\#0 (accessed at Jan. 21, 2018).

Cheng, E. (2015). Aerial Photography and Videography Using Drones. San Francisco, CA: Peachpit Press.

Coifman, B., M. McCord, R. G. Mishalani, M. Iswalt \& Y. Ji. (2006). Roadway traffic monitoring from an unmanned aerial vehicle. IEE Proceedings-Intelligent Transport System, 153(1): 11-20. DOI: 10.1049/ip-its:20055014.

Davison, K. K., \& Lawson, C. T. (2006). Do attributes in the physical environment influence children's physical activity? A review of the literature. International journal of behavioral nutrition and physical activity, 3(1), 19.

Diogenes, M., Greene-Roesel, R., Arnold, L., \& Ragland, D. (2007). Pedestrian counting methods at intersections: a comparative study. Transportation Research Record: Journal of the Transportation Research Board, (2002), 26-30.

Ernawati, J., Adhitama, M. S., \& Sudarmo, B. S. (2016). Urban Design Qualities Related Walkability in a Commercial Neighbourhood. Environment-Behaviour Proceedings Journal, 1(4), 242-250. 
Evenson, K. R., Jones, S. A., Holliday, K. M., Cohen, D. A., \& McKenzie, T. L. (2016). Park characteristics, use, and physical activity: A review of studies using SOPARC (System for Observing Play and Recreation in Communities). Preventive medicine, 86, 153-166.

Ewing, R., \& Clemente, O. (2013). Measuring urban design: Metrics for livable places. Washington DC: Island Press.

Ewing, R., Hajrasouliha, A., Neckerman, K. M., Purciel-Hill, M., \& Greene, W. (2016). Streetscape features related to pedestrian activity. Journal of Planning Education and Research, 36(1), 5-15.

Ferreira, I., Van Der Horst, K., Wendel-Vos, W., Kremers, S., Van Lenthe, F. J., \& Brug, J. (2007). Environmental correlates of physical activity in youth-a review and update. Obesity reviews, $8(2)$, 129-154.

Figliozzi, M., Monsere, C., Nordback, K., Johnson, P., \& Blanc, B. (2014). Design and Implementation of Pedestrian and Bicycle-Specific Data Collection Methods in Oregon: Pilot Study (No. FHWA-ORRD-14-15).

Finn, R. L., \& Wright, D. (2012). Unmanned aircraft systems: Surveillance, ethics and privacy in civil applications. Computer Law \& Security Review, 28(2): 184-194. http://dx.doi.org/10.1016/j.clsr.2012.01.005.

Gaszczak, A., Breckon, T. P., \& Han, J. (2011). Real-time people and vehicle detection from UAV imagery, Proceedings of the Intelligent Robots and Computer Vision XXVIII: Algorithms and Techniques, San Francisco, CA, USA, 24 January 2011; pp. 536-547.

Ge, W., Collins, R. T., \& Ruback, R. B. (2012). Vision-based analysis of small groups in pedestrian crowds. IEEE transactions on pattern analysis and machine intelligence, 34(5), 1003-1016.

Gehl, J, \& Svarre, B. (2013). How to study public life. Washington, DC: Island Press.

Getzin, S., Wiegand, K. \& Schoning, I. (2012). Assessing biodiversity in forests using very highresolution images and unmanned aerial vehicles. Methods in Ecology and Evolution, 3(2), 397-404. DOI:10.1111/j.2041-210X.2011.00158.x.

Greene-Roesel, R., Diogenes, M. C., Ragland, D. R., \& Lindau, L. A. (2008). Effectiveness of a commercially available automated pedestrian counting device in urban environments: Comparison with manual counts. Safe Transportation Research \& Education Center.

Gwet, K. L. (2014). Handbook of inter-rater reliability: The definitive guide to measuring the extent of agreement among raters. Advanced Analytics, LLC.

Hajrasouliha, A., \& Yin, L. (2014). The impact of street network connectivity on pedestrian volume. Urban Studies, 52(13), 2483-2497.

Hamidi, S. and Moazzeni, S. (2018). Examining the Impacts of Street-Level Built Environmental and Urban Design Qualities on Walking Behavior in Downtown Dallas, TX, Transportation Research Board 97th Annual Meeting. 
Jacobs, J. (1961). The death and life of great American cities. New-York, NY: Vintage.

Kanistras, K., Martins, G., Rutherford, M. J., \& Valavanis, K. P. (2014). Survey of unmanned aerial vehicles (uavs) for traffic monitoring. In Handbook of Unmanned Aerial Vehicles (pp. 2643-2666). Springer Netherlands.

Kilambi, P., Ribnick, E., Joshi, A. J., Masoud, O., \& Papanikolopoulos, N. (2008). Estimating pedestrian counts in groups. Computer Vision and Image Understanding, 110(1), 43-59.

Lee, J., Zhong, Z., Kim, K., Dimitrijevic, B., Du, B., \& Gutesa, S. (2015). Examining the Applicability of Small Quadcopter Drone for Traffic Surveillance and Roadway Incident Monitoring. In Transportation Research Board 94th Annual Meeting (No. 15-4184).

Lenhart, D. O. M. I. N. I. K., Hinz, S. T. E. F. A. N., Leitloff, J. E. N. S., \& Stilla, U. (2008). Automatic traffic monitoring based on aerial image sequences. Pattern Recognition and Image Analysis, 18(3), 400-405.

Li, Y. (2008). Vehicle extraction using histogram and genetic algorithm based fuzzy image segmentation from high resolution UAV aerial imagery. ISPRS08, page B3b, 529.

Lin, Y., Jiang, M., Yao, Y., Zhang, L., \& Lin, J. (2015). Use of UAV oblique imaging for the detection of individual trees in residential environments. Urban Forestry \& Urban Greening, 14, 404-412. http://dx.doi.org/10.1016/j.ufug.2015.03.003.

Ma, Y., Wu, X., Yu, G., Xu, Y., \& Wang, Y. (2016). Pedestrian detection and tracking from lowresolution unmanned aerial vehicle thermal imagery. Sensors, 16(4), 446.

Mahadevan, P., (2010). The military utility of drones. CSS Anal. Secur. Policy, 1-3.

Maxwell, J. A. (2016). Designing for 'life between buildings': modeling the relationship between streetscape qualities and pedestrian activity in Glasgow, Scotland (Doctoral dissertation, University of Strathclyde).

McKenzie, T. L., Marshall, S. J., Sallis, J. F., \& Conway, T. L. (2000). Leisure-time physical activity in school environments: an observational study using SOPLAY. Preventive medicine, 30(1), 70-77.

McKenzie, T. L., Cohen, D. A., Sehgal, A., Williamson, S., \& Golinelli, D. (2006). System for Observing Play and Recreation in Communities (SOPARC): reliability and feasibility measures. Journal of Physical Activity and Health, 3(s1), S208-S222.

McKenzie, T. L., \& Van Der Mars, H. (2015). Top 10 research questions related to assessing physical activity and its contexts using systematic observation. Research Quarterly for Exercise and Sport, 86(1), 13-29.

Mehta, V. (2013). The street: a quintessential social public space. Routledge.

Moranduzzo, T., \& Melgani, F. (2014). Automatic car counting method for unmanned aerial vehicle images. IEEE Transactions on Geoscience and Remote Sensing, 52(3), 1635-1647. 
Ozbay, K., et al. (2010). Automatic Pedestrian Counter. New Jersey Department of Transportation and Federal Highway Administration, FHWA-NJ-2010-001. http://www.nj.gov/transportation/refdata/research/reports/FHWA-NJ-2010-001.pdf (accessed at Jan. 21, 2018).

Ozbil, A., Peponis, J., \& Stone, B. (2011). Understanding the link between street connectivity, land use and pedestrian flows. Urban Design International, 16(2), 125-141.

Papageorgiou, M., Diakaki, C., Dinopoulou, V., Kotsialos, A., \& Wang, Y. (2003). Review of road traffic control strategies. Proceedings of the IEEE, 91(12), 2043-2067.

Park, K. \& Ewing, R. (2017). The usability of unmanned aerial vehicles (UAVs) for measuring parkbased physical activity. Landscape and Urban Planning 167: 157-164. http://dx.doi.org/10.1016/j.landurbplan.2017.06.010.

Portmann, J., Lynen, S., Chli, M., \& Siegwart, R. (2014). People detection and tracking from aerial thermal views. In Robotics and Automation (ICRA), 2014 IEEE Hong Kong, China, 31 May-7 June 2014; pp. 1794-1800.

Rapp, G. C. (2009). Unmanned aerial exposure: Civil liability concerns arising from domestic law enforcement employment of unmanned aerial systems. North Dakota Law Review, 85: 623-648.

Ridgers, N. D., Stratton, G., \& McKenzie, T. L. (2010). Reliability and validity of the System for Observing Children's Activity and Relationships during Play (SOCARP). Journal of Physical Activity and Health, 7(1), 17-25.

Ro, K., Oh, J., Dong, L., (2007). Lessons learned: Application of small uav for urban highway traffic monitoring, 45th AIAA Aerosp. Sci. Meet. Exhib., pp. 1-19. doi:10.2514/6.2007-596.

Rodríguez, D. A., Brisson, E. M., \& Estupiñán, N. (2009). The relationship between segment-level built environment attributes and pedestrian activity around Bogota's BRT stations. Transportation research part D: transport and environment, 14(7), 470-478.

Ryus, P., Ferguson, E., Laustsen, K. M., Schneider, R. J., Proulx, F. R., Hull, T., \& Miranda-Moreno, L. (2014). Guidebook on pedestrian and bicycle volume data collection (NCHRP Report 797). Institute of Transportation Studies, UC Berkeley.

Sallis, J. F. (2009). Measuring physical activity environments: A brief history. American Journal of Preventive Medicine, 36(Suppl. 4), S86-S92. doi:10.1016/j.amepre.2009.01.002

Sasidharan, V. \& McKenzie, T. L. (2014). SOPARNA: System for Observing Physical Activity and Recreation in Natural Areas. San Diego, CA: San Diego State University. Retrieved from https://www.activelivingresearch.org/soparna-system-observing-physical-activity-and-recreationnatural-areas (accessed at June 23, 2018).

Schneider, R., Arnold, L., \& Ragland, D. (2009). Methodology for counting pedestrians at intersections: use of automated counters to extrapolate weekly volumes from short manual counts. Transportation Research Record: Journal of the Transportation Research Board, (2140), 1-12. 
Schneider, R. J., et al. (2012). Development and Application of the San Francisco Pedestrian Intersection Volume Model. Transportation Research Record: Journal of the Transportation Research Board, 2299, $65-78$.

Shrout, P. E., \& Fleiss, J. L. (1979). Intraclass correlations: uses in assessing rater reliability. Psychological bulletin, 86(2), 420-428. doi:10.1037/0033-2909.86.2.420.

Siebert, S., \& Teizer, J. (2014). Mobile 3D mapping for surveying earthwork projects using an Unmanned Aerial Vehicle (UAV) system. Automation in Construction, 41, 1-14.

Southern California Association of Governments (SCAG). (2013). Conducting Bicycle and Pedestrian Counts: A Manual for Jurisdictions in Los Angeles County and Beyond. Retreived from https://media.metro.net/riding_metro/bikes/bikecounttrainingmanual_2.pdf (Accessed at 3/26/2017).

Sung, H., Lee, S., \& Cheon, S. (2015). Operationalizing jane jacobs's urban design theory: Empirical verification from the great city of seoul, korea. Journal of Planning Education and Research, 35(2), 117-130.

Torres-Sanchez, J., Pena, J.M., de Castro, A.I., \& Lopez-Granados, F. (2014) Multi-temporal mapping of the vegetation fraction in early season wheat fields using images from UAV. Computers and Electronics in Agriculture, 103, 104-111, http://dx.doi.org/10.1016/j.compag.2014.02.009.

Transport for London \& Central London Partnership. (2004). Towards a fine city for people: Public spaces and public life_-London 2004. London, UK: Gehl Architects.

U.S. Federal Aviation Administration. (2016) Part 107: Operation and Certification of Small Unmanned Aircraft Systems, effective August 26, 2016.

U.S. Federal Highway Administration. (2013). Traffic monitoring guide. Washington, DC: U.S. Federal Highway Administration.

Vasuki, Y., Holden, E.J., Kovesi, P. \& Micklethwaite, S. (2014). Semiautomatic mapping of geological structures using UAV-based photogrammetric data: An image analysis approach. Computers Geosciences, 69, 22-32. http://dx.doi.org/10.1016/j.cageo.2014.04.012.

Wang, L., Chen, F., \& Yin, H. (2016). Detecting and tracking vehicles in traffic by unmanned aerial vehicles. Automation in Construction, 72, 294-308.

Whyte, W.H., (1980). The social life of small urban spaces. New York, NY: Project for Public Spaces.

Xia, W., Zhang, J., \& Kruger, U. (2015). Semisupervised pedestrian counting with temporal and spatial consistencies. IEEE Transactions on Intelligent Transportation Systems, 16(4), 1705-1715.

Yan, W., \& Forsyth, D. A. (2005, January). Learning the behavior of users in a public space through video tracking. In Application of Computer Vision, 2005. WACV/MOTIONS'05 Volume 1. Seventh IEEE Workshops on (Vol. 1, pp. 370-377). IEEE.

Yin, L., Cheng, Q., Wang, Z., \& Shao, Z. (2015). 'Big data' for pedestrian volume: Exploring the use of Google Street View images for pedestrian counts. Applied Geography, 63, 337-345. 
Yin, L. (2017). Street level urban design qualities for walkability: Combining 2D and 3D GIS measures. Computers, Environment and Urban Systems, 64, 288-296. 

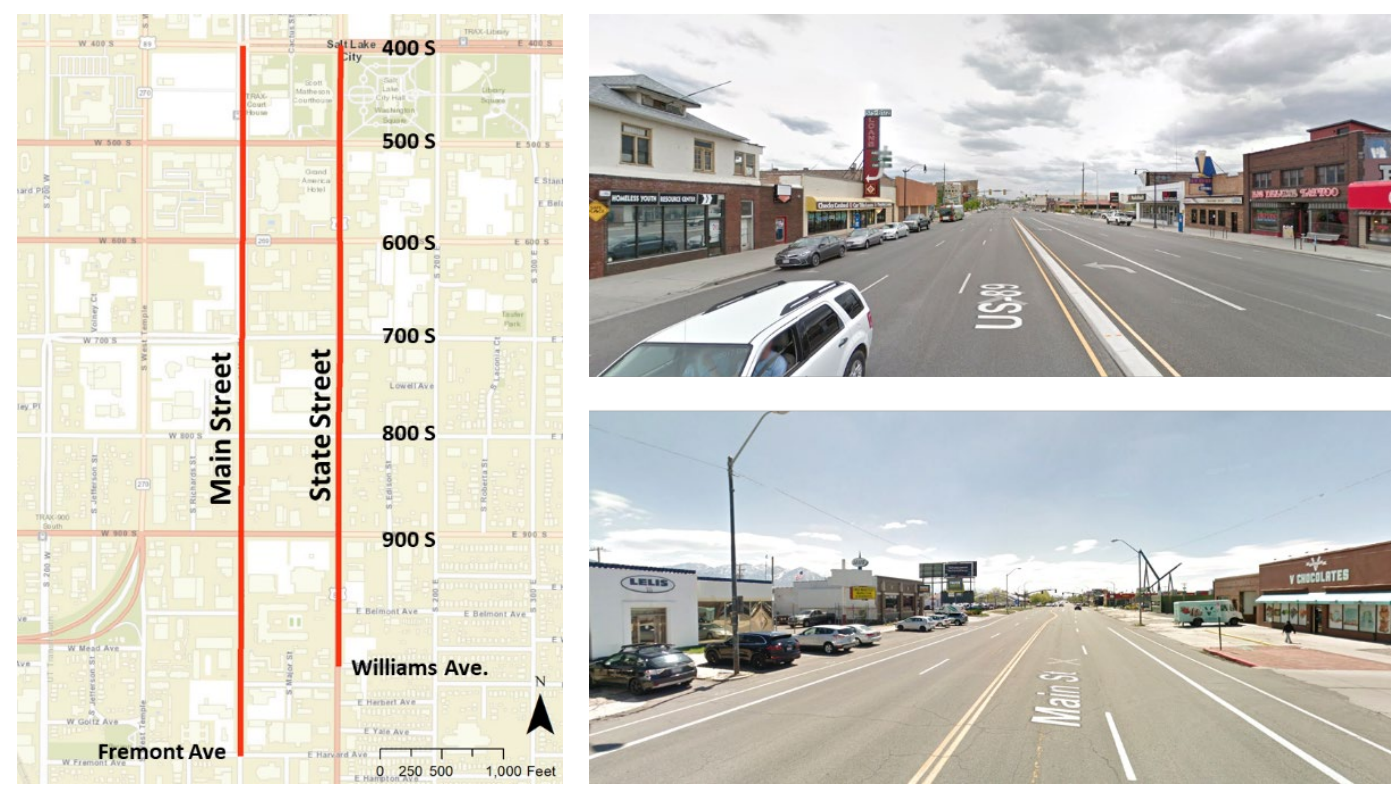

Figure 1. Study site (left) and street views

Source (basemap/image): Esri (left), Google Street View (right) 

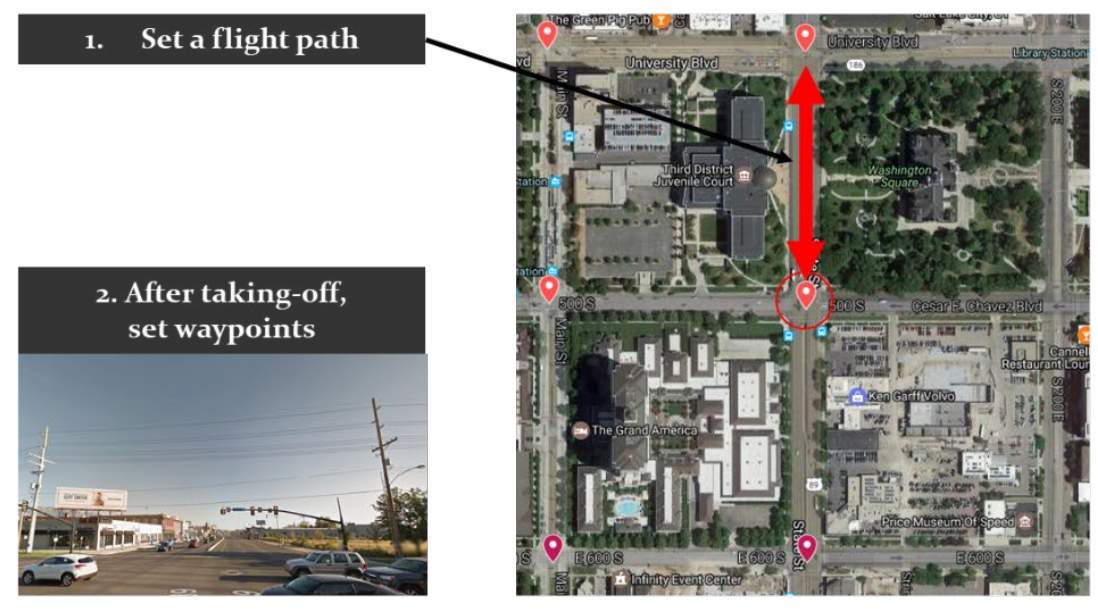

3. Two passes up \& down

$$
\uparrow \uparrow \downarrow \begin{aligned}
& \cdot{ }^{4} \mathrm{mph} \\
& \cdot 5^{0-70} \text { feet }
\end{aligned}
$$

Figure 2. A UAV observation process

Source (basemap): Google Maps 

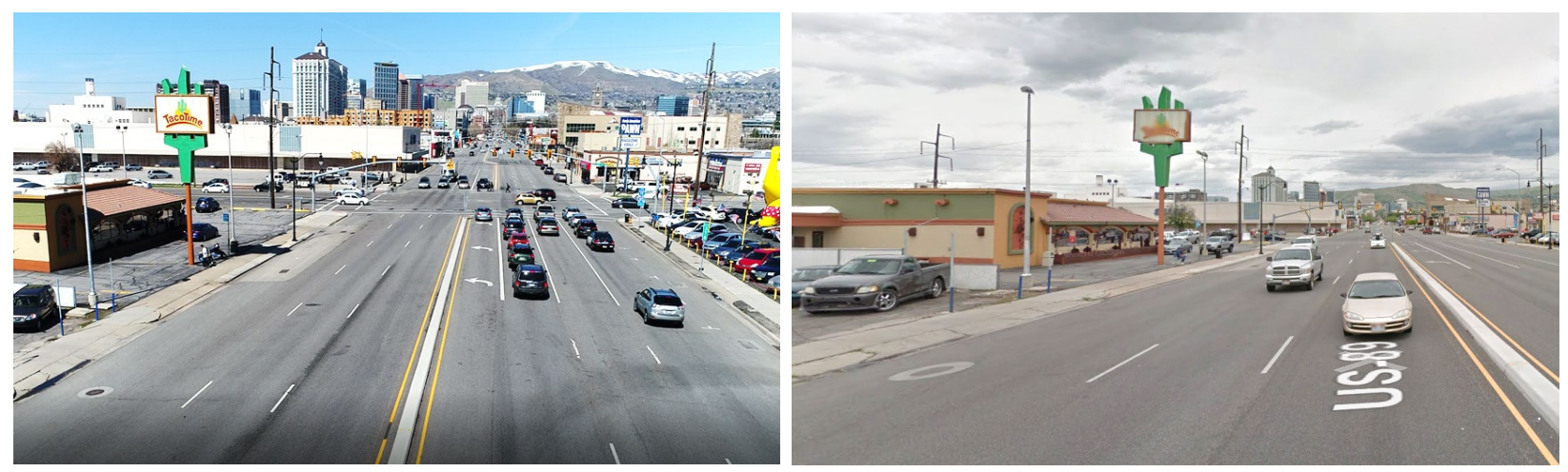

Figure 3. Comparison between UAV view (left) and human-eye-view (right)

Source: author (left), Google Street View (right) 


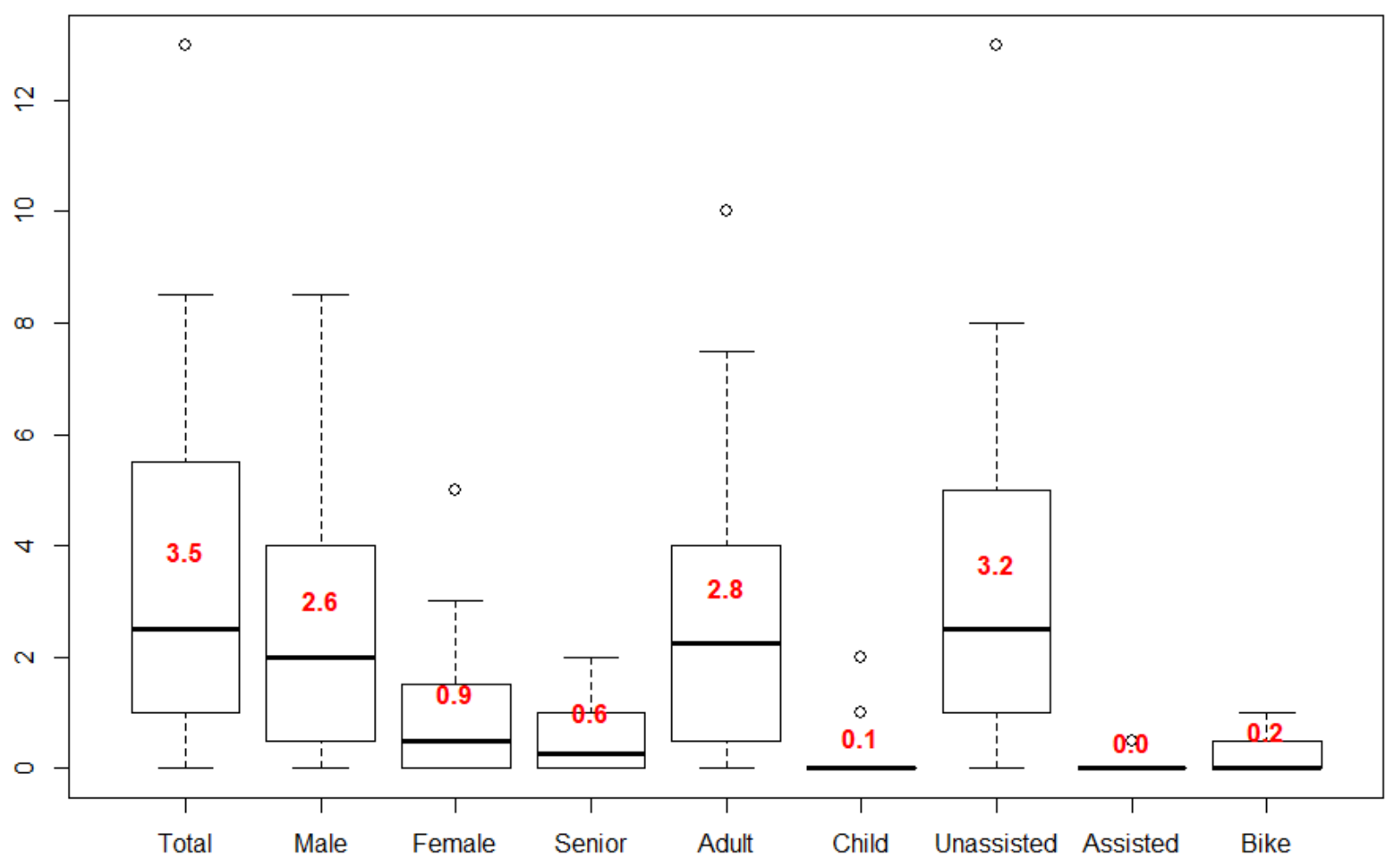

Figure 4. Box plot of UAV observation

Note: red texts are average values for each category 

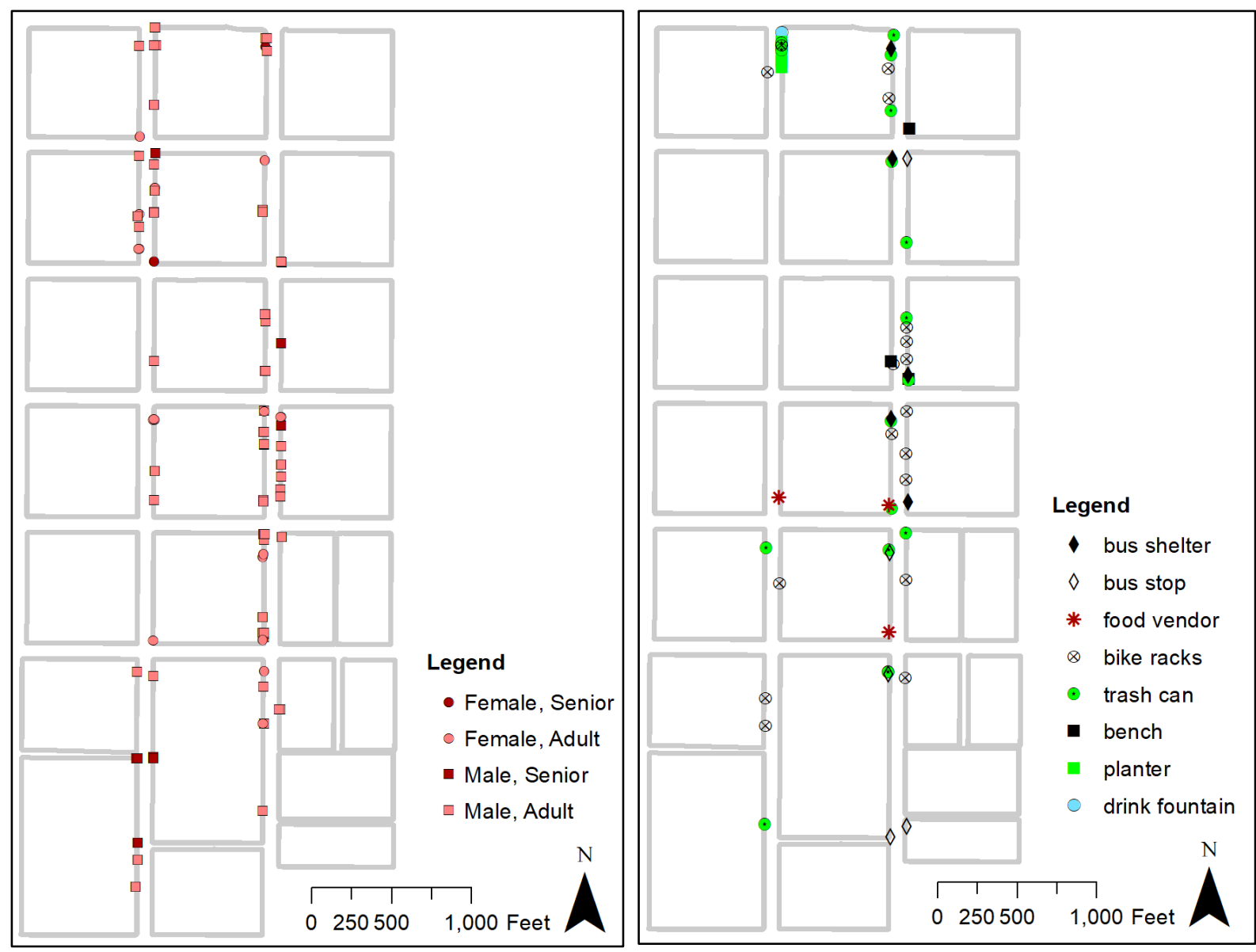

Figure 5. Examples of Mapping from UAV observation processed in ESRI ArcGIS (left: pedestrians, right: street facilities) 
Table 1. Comparison of total time spent for 26 block faces (13 segments) between two observation methods

\begin{tabular}{|lrlr|}
\hline On-the-ground observation & $\begin{array}{l}\text { Time spent } \\
\text { (min.) }\end{array}$ & UAV observation & \multicolumn{1}{c|}{$\begin{array}{l}\text { Time spent } \\
\text { (min.) }\end{array}$} \\
\hline $\begin{array}{l}\text { Observation 1 (one side) - } \\
\text { pre/post setting }\end{array}$ & 26 & $\begin{array}{l}\text { Pre/post setting (e.g. } \\
\text { waypoints, taking off, } \\
\text { landing) }\end{array}$ & 26 \\
\hline $\begin{array}{l}\text { Observation 1 (one side) - } \\
\text { actual observation }\end{array}$ & 71 & $\begin{array}{l}\text { Flights (recording both } \\
\text { sides) }\end{array}$ & 71 \\
\hline $\begin{array}{l}\text { Observation 2 (other side) - } \\
\text { pre/post setting }\end{array}$ & 26 & Video observations & 142 \\
\hline $\begin{array}{l}\text { Observation 2 (other side) - } \\
\text { actual observation }\end{array}$ & 71 & & 239 \\
\hline Total time (min.) & 194 & Total time (min.) & 9.19 \\
\hline $\begin{array}{l}\text { Average minutes per block } \\
\text { face (250m; 820feet) }\end{array}$ & 7.46 & $\begin{array}{l}\text { Average minutes per block } \\
\text { face (250m; 820feet) }\end{array}$ & \\
\hline
\end{tabular}


Table 2. Equivalence Reliability: Cronbach's Alpha Values for UAV Counts Versus Onthe-ground Counts and Web Counts

\begin{tabular}{|llll|}
\hline Category & $\begin{array}{l}\text { UAV Counts vs. } \\
\text { On-the-ground Counts } \\
{[\mathbf{C I}](\mathbf{n}=\mathbf{2 6})}\end{array}$ & $\begin{array}{l}\text { UAV Counts vs. } \\
\text { Google Counts }[\mathbf{C I}] \\
(\mathbf{n}=\mathbf{2 5})\end{array}$ & $\begin{array}{l}\text { UAV Counts vs. } \\
\text { Bing Counts }[\mathbf{C I}] \\
(\mathbf{n}=\mathbf{2 4})\end{array}$ \\
\hline Cronbach's Alpha & $0.97[0.95,0.99]$ & $0.73[0.53,0.94]$ & $0.46[0.04,0.89]$ \\
\hline
\end{tabular}

Note: $[\mathrm{CI}]-95 \%$ confidence interval 
Table 3. Interrater Reliability: Intraclass Correlation Coefficients Between two observers watching UAV video files $(n=26)$

\begin{tabular}{|c|c|c|c|c|}
\hline \multirow[t]{2}{*}{ Category } & & \multicolumn{2}{|c|}{ Average Number of People } & \multirow[t]{2}{*}{$\mathrm{ICC}[\mathrm{CI}]^{1}$} \\
\hline & & $\begin{array}{l}\text { Primary } \\
\text { observer }\end{array}$ & $\begin{array}{l}\text { Secondary } \\
\text { observer }\end{array}$ & \\
\hline Total & & 3.46 & 3.56 & $0.99[0.99,1]$ \\
\hline \multirow[t]{2}{*}{ Gender } & Male & 2.58 & 2.65 & $0.99[0.98,1]$ \\
\hline & Female & 0.88 & 0.90 & $0.94[0.88,0.97]$ \\
\hline Age & Senior & 0.56 & 0.60 & $0.82[0.65,0.92]$ \\
\hline \multirow[t]{2}{*}{ Group } & Adult & 2.79 & 2.83 & $0.99[0.97,0.99]$ \\
\hline & Child & 0.12 & 0.14 & $0.44[0.08,0.71]$ \\
\hline \multirow[t]{3}{*}{$\begin{array}{l}\text { Mode of } \\
\text { transportation }\end{array}$} & $\begin{array}{l}\text { Pedestrian } \\
\text { (unassisted) }\end{array}$ & 3.23 & 3.33 & $0.99[0.99,1]$ \\
\hline & $\begin{array}{l}\text { Pedestrian } \\
\text { (assisted) }\end{array}$ & 0.02 & 0.02 & $\mathrm{~N} / \mathrm{A}^{2}$ \\
\hline & Bicycle & 0.21 & 0.21 & $\mathrm{~N} / \mathrm{A}^{2}$ \\
\hline
\end{tabular}

Note 1: $[\mathrm{CI}]-95 \%$ confidence interval

2: N/A: the ICC were not calculated for too small counts 
Table 4. Comparison of four methods for pedestrian observation

\begin{tabular}{|c|c|c|c|c|}
\hline Method & Human eyes & Video camera & $\begin{array}{l}\text { Automatic } \\
\text { counter }\end{array}$ & $\begin{array}{l}\text { Unmanned aerial } \\
\text { vehicle (UAV) }\end{array}$ \\
\hline Examples & $\begin{array}{l}\text { - Fixed spot (e.g., } \\
\text { intersection) } \\
\text { - Screen line } \\
\text { - Walking } \\
\text { observer }\end{array}$ & $\begin{array}{l}\text { - Stationary } \\
\text { camera } \\
\text { - Dashboard } \\
\text { camera } \\
\text { - Online street } \\
\text { view image }\end{array}$ & $\begin{array}{l}\text { - Infrared sensor } \\
\text { - Induction loop } \\
\text { - Radar sensor } \\
\text { - etc. }\end{array}$ & $\begin{array}{l}\text { - UAV in motion } \\
\text { to cover a } \\
\text { larger area } \\
\text { - UAV in a fixed } \\
\text { location }\end{array}$ \\
\hline Advantages & $\begin{array}{l}\text { - Easy to } \\
\text { implement } \\
\text { - Portable } \\
\text { - Comprehensive } \\
\text { data }\end{array}$ & $\begin{array}{l}\text { - Comprehensive } \\
\text { data } \\
\text { - Accurate } \\
\text { - Image } \\
\text { processing }\end{array}$ & $\begin{array}{l}\text { - Affordable } \\
\text { - Long-term } \\
\text { data collection }\end{array}$ & 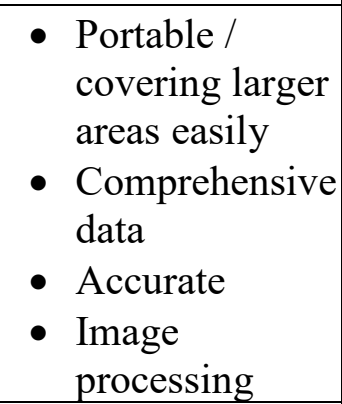 \\
\hline Disadvantages & $\begin{array}{l}\text { - Labor-intensive } \\
\text { - Subjectivity } \\
\text { issue }\end{array}$ & $\begin{array}{l}\text { - Expensive } \\
\text { - Limited view } \\
\text { - Prone to theft } \\
\text { \& malfunctions }\end{array}$ & $\begin{array}{l}\text { - Counting only } \\
\text { - Undercounting } \\
\text { issue }\end{array}$ & $\begin{array}{l}\text { - Short duration } \\
\text { - Subject to poor } \\
\text { weather }\end{array}$ \\
\hline Applications & $\begin{array}{l}\text { - } \text { Quick survey } \\
\text { - Observing larger } \\
\text { areas (e.g., } \\
\text { downtown) } \\
\text { - Collecting both } \\
\text { behavioral and } \\
\text { environmental } \\
\text { information }\end{array}$ & $\begin{array}{l}\text { Observing key } \\
\text { spots for a long } \\
\text { time and } \\
\text { gathering } \\
\text { detailed } \\
\text { information }\end{array}$ & $\begin{array}{l}\text { - Long-term } \\
\text { monitoring of } \\
\text { pedestrian } \\
\text { traffic } \\
\text { - Comparative } \\
\text { survey across } \\
\text { different areas }\end{array}$ & $\begin{array}{l}\text { - } \text { Observing } \\
\text { larger areas } \\
\text { (e.g., } \\
\text { downtown) } \\
\text { - Collecting both } \\
\text { behavioral and } \\
\text { environmental } \\
\text { information } \\
\text { - Repetitive } \\
\text { survey to see } \\
\text { temporal } \\
\text { variation (e.g., } \\
\text { season, year) }\end{array}$ \\
\hline
\end{tabular}

